\title{
Tumor Desmoplastic Stroma - Its Utility as A Prognostic Marker for Breast Carcinoma
}

\author{
Vaddatti Tejeswini, B Chaitra*, P Premalatha, I V Renuka, R Vaishnavi and B Manasa \\ Dept of pathology, NRI Medical College, Guntur, Andhra Pradesh, INDIA
}

\begin{abstract}
Background: Breast cancer is the second most common malignancy in women, affecting more than 1 million worldwide annually and is the most frequent cause of cancer related deaths in women. Dynamic interactions between neoplastic epithelial cells and the surrounding stroma can select stromal cells that modulate tumor behavior. The interplay between a tumor and its environment is exemplified by the morphological changes observed in the stroma of human breast cancer. Hence in this study we tried to evaluate a grading system for tumor desmoplasia and its role as a prognostic marker for breast cancer.
\end{abstract}

Methods: This is a retrospective study including 102 primary invasive breast malignancy diagnosed at a tertiary care hospital between January 2015 to September 2017. The cases with prior chemotherapy and radiotherapy were excluded. In all the cases hematoxylin \& eosin stained slides were retrieved and assessed for desmoplastic stromal categorization, tumor grade and axillary lymph nodal involvement. The status of immunohistochemistry for ER, PR \&, Her2 neu were tabulated. The association of desmoplastic stroma was evaluated with other known prognostic factors. $\mathrm{p}$ value calculated, $\mathrm{p}<0.05$ considered significant.

Results: There was statistically significant association of the type of desmoplastic stroma with the tumor grade, tumor size and metastatic axillary lymphnode.

Conclusion: This emphasizes the role of stromal desmoplasia in tumor progression and prognosis. Hence we conclude that a special mention to be made on the type of desmoplasia in the histopathology report of all breast cancer.

\section{Keywords: Breast Carcinoma, Tumor Desmoplasia, Prognosis, Immunohistochemistry}

\section{Introduction}

Breast cancer is the second most common malignancy and most frequent cause of cancer related deaths in women with an incidence of more than 1 million worldwide annually. Breast cancer has become the most common cancer amongst women in India.[1] Dynamic interactions between neoplastic epithelial cells and the surrounding stroma can select stromal cells that modulate tumor behavior.[2,3,4] It is now well recognised that cancer initiation, growth and progression is dependent on tumour microenvironment of which tumour-stroma is an integral part [5] The interplay between a tumor and its environment is exemplified by the morphological changes observed in the stroma of human breast cancer [6]. Hence the type of stroma in breast cancers could either favour or inhibit invasion and metastasis. This study was conducted to evaluate the role of type of desmoplastic stroma in prognosis of breast carcinoma.

Aim and Objectives 1) To grade the type of desmoplastic reaction and 2) To assess the utility of different grades of desmoplasia as prognostic indicators

\section{Materials and Methods}

This is a retrospective study conducted in a tertiary care hospital during January 2015 and August 2017. One hundred and two mastectomy specimens of 101 cases diagnosed with primary breast carcinoma were included. The details regarding the age, side, tumor size, NBR grading, lymph node metastasis were retrieved from the registers. Hematoxylin and eosin stained smears were assessed for the type of desmoplasia. The categorisation of fibrotic stroma was done at the invasive zone and according to most unfavourable stromal area. The immunohistochemistry data and slides were reviewed and analysis tabulated.

\section{Criteria for histological categorisation of fibrotic cancer stroma [7].}

Grade I Mature -fine and elongated collagen fibres with fibrocytes stratified into multiple layers

Grade II Intermediate- broad bands of collagen with brightly eosinophilic hyalinisation, similar to those seen in a keloid, were intermingled with mature collagen fibres

Grade III Immature - randomly orientated keloid-like collagen bundles surrounded by loose stroma.

\section{Inclusion criteria}

All primary breast carcinomas with radical mastectomy 
Cases with immunohistochemistry for ER, PR and Her2neu

\section{Exclusion criteria}

Cases with prior chemo and radiotherapy were excluded

Core needle biopsies of breast lesions

Statistical analysis Chi square analysis was done to evaluate the significance of difference between association of variables like stromal desmopalstic reaction with nodal metastasis, tumor grade, tumor size, age, ER, PR and Her2neu. The $\mathrm{p}$ value calculated and $<0.5$ considered significant.

\section{Results}

This study was conducted to analyse the tumor desmoplastic stroma as a prognostic marker for carcinoma breast. The age range varied with peak incidence between $46-55 \mathrm{yr}$. The incidence in various age groups is indicated in table 1. There was slight preponderance to right side with 56 cases $(54.9 \%)$. There were several histological variants, of which the most common type was infiltrating ductal carcinoma as depicted in table 2 . The various prognostic factors like tumor size and lymph nodal involvement were evaluated. The stromal desmoplastic reaction was evaluated in all cases and grading done accordingly. In this study, it was observed that $49.02 \%$ of cases had an intermediate type of desmoplastic stroma, 33.33\% had a mature desmoplastic stroma and $17.65 \%$ cases showed an immature stroma. Figures 1, 2 and 3 show the grade 1, 2 and 3 of tumor desmoplasia. The cases were also classified according to tumor size, nodal involvement and IHC markers ER, PR and Her2neu.

Out of all the cases of grade 3 tumors, immature desmoplastic stroma seen in 55.55\%, intermediate desmoplasia in $33.33 \%$ and mature stroma in $11.11 \%$ of cases

Tumor size and nodal status was classified taking TNM staging into consideration, T0 primary tumor not assessed, $\mathrm{T} 1<2 \mathrm{~cm}, \mathrm{~T} 22-5 \mathrm{~cm}, \mathrm{~T} 3>5 \mathrm{~cm}$ and $\mathrm{T} 4-$ tumor of any size with direct extension to the chest wall and to the skin or inflammatory breast carcinoma. N0- no metastasis, N1metastasis in 1-3 axillary lymphnodes, N2 metastasis in 4-9 axillary lymph nodes and N3 >= 10 lymphnodal involment. Majority of the cases belonged to T2 with $63.73 \%$ of cases, followed by T1, T3, T4 with $23.53 \%, 11.76 \%$ and $0.98 \%$ respectively. There was correlation between size of tumor and desmoplasia. The immature desmoplastic stroma was observed in $4.17 \%, 17.46 \%$ and $42.85 \%$ in $\mathrm{T} 1, \mathrm{~T} 2$ and T3 lesions respectively. Larger tumors showed increased percentage of immature desmoplastic stroma.

The majority of cases were of N0 followed by N1, N2 and N3. Axillary lymphnodes were free from tumor infiltration in $51.96 \%$ cases and tumor infiltration noted in $48.04 \%$ of cases. Table 4 shows that mature, intermediate and immature stromal desmoplastic reaction have $29.41 \%$, $54 \%$ and $66.67 \%$ of axillary metastasis respectively ( $p$ -0.019). There was stastistically significant correlation between axillary lymph nodal involvement and grading of desmoplasia.

The IHC analysis is depicted in table 3. All the prognostic indicators were analysed with type of desmoplastic stroma and chi square calculated. There was statiscally significant correlation of type of desmoplasia with tumor size, lymph nodal involvement and grade of tumor as in table 4. No statistically significant correlation was seen with age, ER, PR, Her2neu status.

Table 1: Spectrum of breast carcinoma in various age groups.

\begin{tabular}{|c|c|c|}
\hline Age in years & No of cases & 21.57 \\
\hline $36-45$ & 22 & 31.37 \\
\hline $46-55$ & 32 & 26.47 \\
\hline $56-65$ & 27 & 19.61 \\
\hline $66-75$ & 20 & 0.98 \\
\hline $76-85$ & 1 & 100.00 \\
\hline
\end{tabular}

Table 2: Spectrum of various histopathological diagnosis.

\begin{tabular}{|c|c|c|}
\hline Diagnosis & No of cases & $\%$ \\
\hline Encysted Papillary Carcinoma & 1 & 0.98 \\
\hline Invasive Ductal Carcinoma & 93 & 91.18 \\
\hline
\end{tabular}




\begin{tabular}{|c|c|c|}
\hline Diagnosis & No of cases & \% \\
\hline $\begin{array}{c}\text { Invasive Ductal Carcinoma with } \\
\text { Fibrocystic disease }\end{array}$ & 1 & 3.98 \\
\hline Invasive Papillary Carcinoma & 4 & 1.96 \\
\hline Mucinous Carcinoma & 2 & 0.98 \\
\hline Well differentiated Papillary carcinoma & 1 & 100.00 \\
\hline Total & 102 & \\
\hline
\end{tabular}

Table 3: Spectrum of Immunohistochemal analysis.

\begin{tabular}{|c|c|c|c|}
\hline & ER & PR & HER 2 \\
\hline Negative & $25(24.51 \%)$ & $34(33.33 \%)$ & $21(20.59 \%)$ \\
\hline Positive & $77(75.49 \%)$ & $68(66.67 \%)$ & $81(79.41 \%)$ \\
\hline Total & 102 & 102 & 102 \\
\hline
\end{tabular}

Table 4: Association of type of desmoplastic stroma with various prognostic markers.

\begin{tabular}{|c|c|c|c|c|c|}
\hline $\begin{array}{l}\text { Parameter/ type of } \\
\text { stromal desmoplasia }\end{array}$ & Grade 1 mature & $\begin{array}{c}\text { Grade 2 } \\
\text { intermediate }\end{array}$ & Grade 3 immature & Chi square & $p$ value \\
\hline $\begin{array}{l}\text { Age } \\
<=53 \\
>53\end{array}$ & $\begin{array}{l}13 \\
21\end{array}$ & $\begin{array}{l}21 \\
29 \\
\end{array}$ & $\begin{array}{l}12 \\
6 \\
\end{array}$ & 4.22 & 0.121 \\
\hline $\begin{array}{l}\text { NBR tumor grade } \\
\text { I } \\
\text { II } \\
\text { III }\end{array}$ & $\begin{array}{c}14 \\
19 \\
1\end{array}$ & $\begin{array}{c}21 \\
26 \\
3\end{array}$ & $\begin{array}{l}6 \\
3 \\
5\end{array}$ & 10.1 & $\begin{array}{c}0.039 \\
\text { (Significant) }\end{array}$ \\
\hline $\begin{array}{l}\text { Tumor size } \\
\text { T1 } \\
\text { T2 } \\
\text { T3 } \\
\text { T4 }\end{array}$ & $\begin{array}{c}6 \\
24 \\
3 \\
1\end{array}$ & $\begin{array}{c}17 \\
28 \\
5 \\
0\end{array}$ & $\begin{array}{c}1 \\
11 \\
6 \\
0\end{array}$ & 14.1 & $\begin{array}{c}0.028 \\
\text { (Significant) }\end{array}$ \\
\hline $\begin{array}{l}\text { Lymph node status } \\
\text { Negative N0 } \\
\text { Positive N1-3 }\end{array}$ & $\begin{array}{l}24 \\
10 \\
\end{array}$ & $\begin{array}{l}23 \\
27 \\
\end{array}$ & $\begin{array}{c}6 \\
12 \\
\end{array}$ & 7.94 & $\begin{array}{c}0.019 \\
\text { (Significant) }\end{array}$ \\
\hline $\begin{array}{l}\text { ER } \\
\text { Negative } \\
\text { Positive }\end{array}$ & $\begin{array}{c}8 \\
26 \\
\end{array}$ & $\begin{array}{l}11 \\
39 \\
\end{array}$ & $\begin{array}{c}6 \\
12 \\
\end{array}$ & 0.945 & 0.62 \\
\hline $\begin{array}{l}\text { PR } \\
\text { Negative } \\
\text { Positive }\end{array}$ & $\begin{array}{l}10 \\
24\end{array}$ & $\begin{array}{l}17 \\
33\end{array}$ & $\begin{array}{c}7 \\
11 \\
\end{array}$ & 0.495 & 0.781 \\
\hline $\begin{array}{l}\text { Her2 neu } \\
\text { Negative } \\
\text { Positive }\end{array}$ & $\begin{array}{c}7 \\
27\end{array}$ & $\begin{array}{l}10 \\
40\end{array}$ & $\begin{array}{c}4 \\
14\end{array}$ & 0.4000 & 0.98 \\
\hline
\end{tabular}




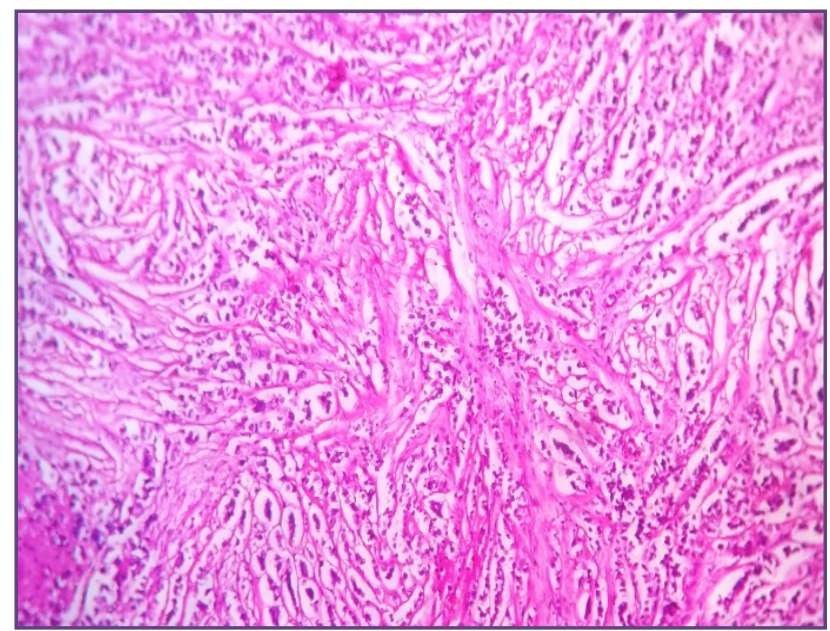

Fig.1: H\&E 100X, Grade 1 desmoplastic stroma-Maturefine and elongated collagen fibers with fibrocytes stratified into multople layers

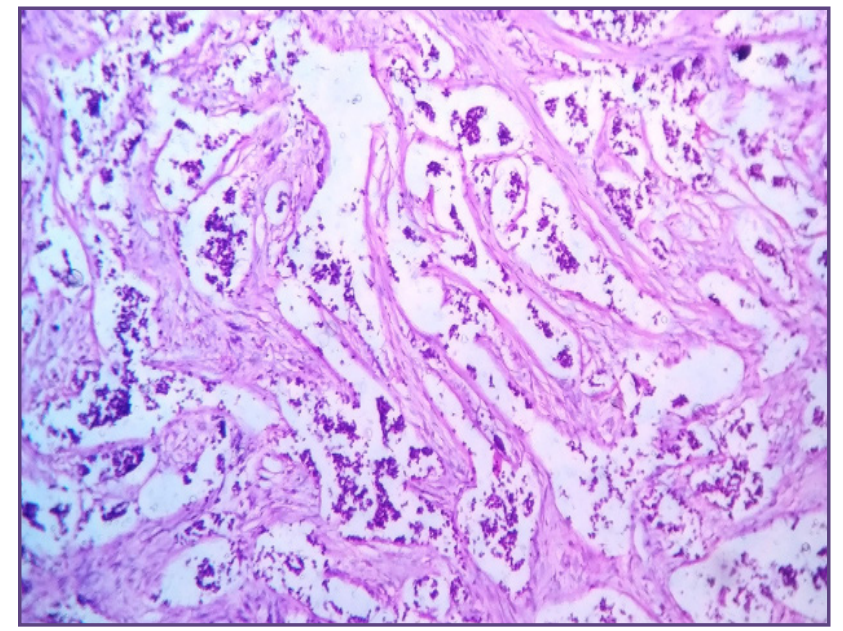

Fig.2: H\&E 100X, Grade 2 desmoplastic stroma-broad bands of cllagen with brightly eosinophilic hyalinisation, sumilar to those seen in a keloid, were intermingled with mature collagen fibres.

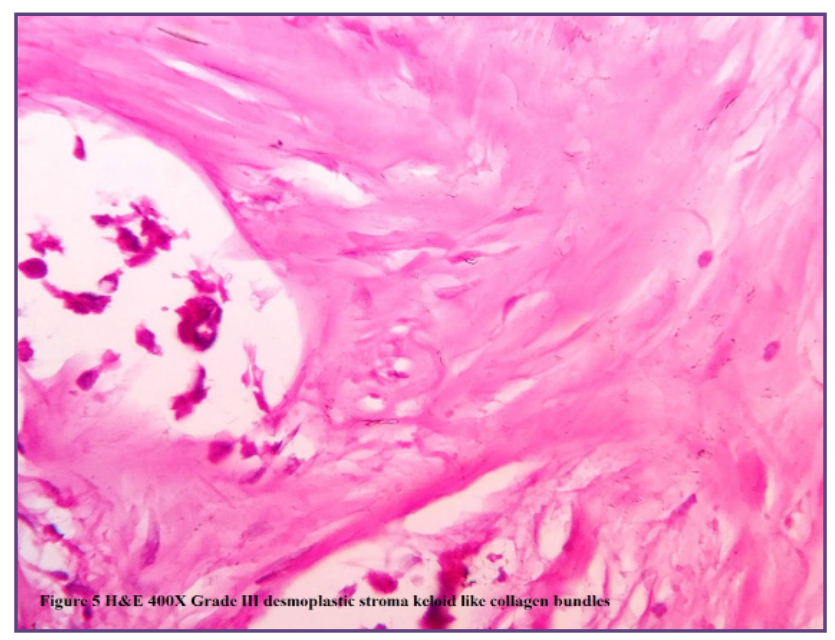

Fig.3: H\&E 400X, Grade III desmoplastic stroma keloid like collagen bundles.

\section{Discussion}

The cascade of enzymatic interactions in the tumor environment play a major role in the metastasis of the tumor. The malignant tumor cells detach from the primary tumor, adhere to components of the extracellular matrix, degrade them, and move through the stroma. This process is either favoured or inhibited by the morphological and biochemical modifications of the different stromal components (cellular and noncellular). Metastatic potential is partly determined by the presence of stromal cells with in the tumor. [5] Therefore, histopathological modifications of the stroma in response to a tumor could shed light on the biological mechanisms involved in invasion and metastasis.[6] Antiangiogenic effect is seen with inhibition of collagen metabolism,[8] hence collagen plays a vital role in tumor angiogenesis and nodal metastasis. [9]

The stromal desmoplastic reaction was classified histologically by Ueno et al (2004)[7] in advanced rectal cancer into mature, intermediate and immature taking qualitative characteristics of the stromal collagen into consideration.[7] The same categorisation was applied to breast cancer by Mariam shadan etal. [10]

In the present study statistically signicant correlation was noted in axillary nodal involvement and the grade of desmoplastic stroma. There was increased risk of axillary nodal metastasis with immature stroma. This was similar to the study done by Mariam shadan etal.[10] The linear 
arrangement of collagen fibers foster breast cancer cell migration into extra cellular matrix and promote invasion in early stages of cancer. [11] whereas studies done by Wernicke et al concluded that invasion is permissible more with loose and myxoid stroma when compared to dense sclerotic stroma.[12] According to Liotta et al there is increased chance of invasion and recurrence with intermediate or immature stroma, $[7,12,13]$, whereas mature and fibrotic stroma can show either increased or decreased chance of invasion[ 13].

This study also showed a strong statistical correlation between the tumor grade and desmoplastic stroma. The immature stroma was the most frequent pattern in grade III tumors constituting to $55.56 \%$. Grade I and II tumors predominantly showed intermediate desmoplasia. Higher the grade of tumor, the stroma is of immature type. This was in accordance with Mariam shadhan et al.[10] This would be useful in predicting the grade of tumor by assessing the pattern of stromal desmoplasia. The same can be applied to core biopsies also and can assess the tumor preoperatively, which would help in planning the treatment. According to Liotta etal, the mature or fibrotic stroma is associated both with increased and decreased aggressive nature of tumor,[13] while uneo etal and wernicke et al showed immature stroma was associated with invasion, poor prognosis and increased chance of recurrence.[7,12] The tumor grade and desmoplastic stroma was not correlated in these studies.

There was statistically significant correlation between tumor size and the type of desmoplastic stroma. The larger tumors predominantly showed immature desmoplastic stroma. In studies done by Mariam shadan et al, there was no significant correlation between tumor size and type of desmoplasia.[10]

This study did not show a significant correlation of age of the patient or IHC markers ER, PR, Her2neu and type of desmoplastic stroma. The studies in breast cancer are mainly focused on lymph nodal metastasis, size and grade of tumor. To our knowledge this is the only work thus for assessing stromal desmoplasia with IHC markers. Other studies are done examining tumor stromal ratio with oestrogen receptor positivity.[14]

In this study we found that the type of desmoplastic stroma in breast cancer is associated with adverse prognostic indicators like tumor size, tumor grade and axillary lymph nodal involvement. Hence changes in desmoplastic stroma helps to identify high risk groups. However, further studies are required to know whether nature of desmoplastic stroma can be used as a prognostic marker in carcinoma breast. However, our data needs to be confirmed by larger studies. The limitations of this study were no records regarding follow up and patient survival rates.

\section{Conclusion}

The type of stromal desmoplasia can be used to predict the tumor grade, axillary nodal status and tumor size. Hence they can be used as prognostic indicators and assess the outcome. These stromal parameters can be applied to core biopsies and assess the tumor preoperatively. There is definite role of alignment of collagen, extra cellular matrix and stromal cells in invasion. Further understanding these processes will present new insights to diagnose, predict and treat breast cancer.

\section{Acknowledgements}

We would like to acknowledge our beloved Principal Dr NVS Chowdary, Dr Muralidhar Reddy, Professor \& HOD of Anatomy for granting ethical clearance and Mrs Saritha, Statistician at NRI Medical College for her prompt analysis.

\section{References}

1. Globocan (2012): World Health Organisation: http:// globocan.iarc.fr/Pages/fact_sheets_cancer.aspx

2. Matrisian LM, Cunha GR, Mohla S. Epithelial-stromal interactions and tumor progression: meeting summary and future directions. Cancer Res 2001;61:3844-6.

3. Shekhar MP, Werdell J, Santner SJ, Pauley RJ, Tait L. Breast stroma plays a dominant regulatory role in breast epithelial growth and differentiation: implications for tumor development and progression. Cancer Res 2001;61:1320-6.

4. Bissell MJ, Barcellos-Hoff MH. Theinfluence of extracellular matrix on gene expression: is structure the message? J Cell Sci Suppl 1987;8:327-43.

5. Downey CL, S A Simpkins, J White, D L Holliday, J L Jones, L B Jordan, J Kulka, S Pollock, S S Rajan, H H Thygesen, A M Hanby and V Speirs The prognostic significance of tumour-stroma ratio in oestrogen receptor-positive breast cancer British journal of cancer 2014, 110 1744-1747/ doi: $10.1032 /$ bjc. 2014.69

6. Mario Wernicke, Laura Cecilia Piñeiro, Daniela Caramutti, Vanesa G. Dorn, Maria Marta Lopez Raffo, Hector G. Guixa, Margarita Telenta, Ana Alcestes Morandi, Breast Cancer Stromal Myxoid Changes Are Associated with Tumor Invasion and Metastasis: A Central Role for Hyaluronan. The United States and Canadian Academy of Pathology, Inc. 2003:16:99

7. Ueno H, JonesAM,Wilkinson KH.Histological categorisation of fibrotic cancer stroma in advanced rectal cancer.Gut. 2004;53:581-586.

8. ME Maragoudakis et al. Basement Membrane Biosynthesis as a Target for Developing Inhibitors of Angiogenesis With Anti-Tumor Properties .Kidney Int.1993; 43 (1): 147-150. 
9. Fang M, Yuan J, Peng C. Collagen as a double-edged sword in tumor progression. Tumor Biol. 2014; 35:2871-2882.

10. Mariam Shadan, Nazoora Khan, Mohammad Amanullah Khan2, Hena Ansari, Sufian Zaheer. Histological categorization of stromal desmoplasia in breast cancer and its diagnostic and prognostic utility SSRG International Journal of Medical Science (SSRG-IJMS) - Vol 4 Issue 6 - June 2017

11. Wyckoff JB, Wang Y, Lin EY. Direct visualization of macrophage-assisted tumor cell intravasation in mammary tumors. Cancer Res. 2007;67:2649-56.
12. Wernicke M, Piñeiro LC, Caramutti D. Breast cancer stromal myxoid changes are associated with tumor invasion and metastasis: A central role for Hyaluronan. Mod Pathol. 2003;16(2):99-107.

13. Liotta LA, Rao CN, Barsky SH. Tumor invasion and the extracellular matrix. Lab Invest. 1983;49:636-49.

14. W E Mesker, T J A Dekker, E M de Kruijf, C C Engels, G W van Pelt, V T H B M Smit and R A E M Tollenaar The prognostic significance of tumour-stroma ratio in oestrogen receptor-positive breast cancer. British Journal of Cancer (2015) 112, 1832-1833 | doi: 10.1038/bjc.2014.570

\section{*Corresponding author:}

Dr B Chaitra, Assistant Professor of pathology, NRI Medical College, Guntur, Andhra Pradesh, India 522503

Phone: +91 9676811386

Email: dr.chaitra.b@gmail.com

Financial or other Competing Interests: None. 